\title{
LICENCIATURA EM DESPORTO - IMPACTOS DA PRECARIZAÇÃO DO TRABALHO NA CIDADE DA GUARDA EM PORTUGAL
}

\author{
DEGREE IN SPORTS - IMPACTS OF WORK PRECARIOUSNESS IN THE CITY OF \\ THE GUARDA IN PORTUGAL
}

\begin{abstract}
B.B. ROCHA ${ }^{1, *}$, F.A. TOLEDO ${ }^{2}$
1 Universidade Federal de Lavras - Programa de Pós-Graduação em Educação. Lavras, Minas Gerias, Brasil

2 Instituto Federal do Sudeste de Minas Gerais, Campus Barbacena - Mestrado em Educação, Barbacena, Minas Gerais, Brasil.
\end{abstract}

\author{
ARTICLE INFO \\ Article history: \\ Received 2018-07-02 \\ Accepted 2018-08-17 \\ Available online 2018-08-31 \\ ${ }^{*}$ Autor correspondente: \\ E-mail: bruuna_rocha1@hotmail.com
}

Palavras-chave: Precarização. flexibilização. Licenciados em

Desporto.

RESUMO. O estudo se desenvolveu através do Programa de Mobilidade Internacional do Instituto Federal do Sudeste de Minas Gerais que teve como objetivo promover a complementação da formação acadêmica para estudantes dos cursos superiores, proporcionando um elo com Instituto Politécnico da Guarda em Portugal em busca de saberes, experiências e conhecimentos. Tivemos como objetivo central realizar um levantamento sobre as condições de trabalho a que estão submetidos os profissionais da área de Educação Física em Portugal, levando em conta a forma como o mundo do trabalho vem se reorganizando em um contexto de globalização, flexibilização e neoliberalismo. Para tanto, realizamos entrevista semi-estruturada com vinte e sete profissionais formados em licenciatura em desporto com questões relativas à a) Formação profissional; b) Condições objetivas de trabalho; c) Relações trabalhistas e d) Saúde. Os resultados apontam que 0 mercado de trabalho em Desporto ainda sofre com influências históricas como a reestruturação produtiva e o neoliberalismo, que faz com que os trabalhadores enfrentem a flexibilização e a precarização.

ABSTRACT. The study was developed through the International Mobility Program of the Federal Institute of Southeastern Minas Gerais which aimed to promote the complementation of academic formation for students of higher education, providing a link with Guarda Polytechnic Institute in Portugal in search of wisdom, experiences and knowledge. Our main objective was to carry out a survey on the working conditions to which the professionals of Physical Education in Portugal are submitted, considering the way the world of work has been reorganized in a context of globalization, flexibilization and neoliberalism. To do so, we conducted a semi- 
structured interview with twenty-seven professionals graduated in sports degree with questions related to a) Professional degree; b) objective conditions of work; c) Labor relations and d) Health. The results indicate that the labor market in sports still suffers from historical influences such as productive restructuring and neoliberalism, which causes workers to face flexibilization and precariousness.

\section{Introdução}

A presente pesquisa foi desenvolvida através do programa Mobilidade Internacional do Instituto Federal do Sudeste de Minas Gerais onde havia como intuito a complementação acadêmica de estudantes no exterior. O objetivo da pesquisa é compreender o mundo trabalho na atual fase de desenvolvimento capitalista e em especial, as condições de trabalho em que se encontra o licenciado em desporto em Portugal na cidade da Guarda.

Os licenciados em desporto são os trabalhadores que realizam a avaliação e controle do treino, estabelecem e orientam programas de treino desportivo e preparação física, participam de atividades e federações desportivas, ginásios, escolas formativas, integram equipes promovendo saúde, a nível empresarial, autárquico, mediático ou associativo.

O modo de produção capitalista está interligado com a exploração do trabalho vivo. Acontece então, um constante processo de acumulação e valorização do capital. Suas crises são caracterizadas pela impossibilidade de extrair maiores lucros, acarretando também a dificuldade do crescimento do mesmo, interferindo na sua expansão e no seu desenvolvimento.

Quando ocorre a crise, é necessário que o sistema capitalista se reconstitua. Sendo assim, ele organiza-se de acordo com a atual nova força de trabalho efetiva como resultante do desequilíbrio gerado pela crise.

Sendo assim, o objetivo do trabalho foi verificar qual a condição de trabalho dos Licenciados em Desporto na cidade da Guarda, notando as transformações no mundo do trabalho. $O$ estudo foi realizado com vinte e sete profissionais formados em Licenciatura em Desporto que exercem seus trabalhos em diferentes áreas ligadas a Educação Física.

A disciplina Educação Física sofreu e ainda passa por dificuldades em sua identidade, o mundo do trabalho coloca os indivíduos a enfrentarem mudanças para se adequarem ao capital. Quando partimos para um patamar que envolve outro país, no caso Portugal, a pesquisa nos revelou o mercado de trabalho na Guarda também é marcado pela flexibilização. 


\title{
2. Fundamentação
}

Levando-se em conta essas determinações, podem-se verificar as acentuadas mudanças que sofreu o modelo de produção capitalista, a partir da década de 1970, em consequência da crise do modelo de acumulação taylorista-fordista e do Estado de Bem Estar Social.

O desenvolvimento capitalista é marcado por crises cíclicas. A crise de 1970 é marcada pela crise do petróleo, pelo fortalecimento dos sindicatos durante o período de expansão capitalista (era de ouro) e pela intensificação das lutas sociais dos anos de 1960. Antunes (1999 apud Coimbra, 2009, p. 75) destaca que as manifestações dessa crise estrutural são:

\begin{abstract}
a) O esgotamento do padrão de acumulação Taylorista/Fordista, b) hipertrofia da esfera financeira, que adquirira certa independência frente ao capital produtivo; c) maior concentração de capitais, conquistada mediante as fusões entre empresas monopolistas e oligopolistas; d) crise do Estado de Bem Estar Social, e a conseqüente retração dos gastos públicos e sua transferência para a iniciativa privada; e) incremento acentuado das privatizações; f) tendência às desregulamentações do processo de trabalho, dos mercados e da força de trabalho. ANTUNES (1999 apud COIMBRA, 2009, p. 75)
\end{abstract}

As mercadorias e os produtos eram produzidos em grande escala, era necessário um mercado capacitado para atender essa produção, sendo característica dele a elaboração e realização dinâmica. O estado se torna "dinamizador" da economia, fornecendo incentivo para bens públicos e para a produção, investindo também em infraestrutura e na aplicação maximizada da mão de obra, buscando ensejos do pleno emprego. Então, o Estado de Bem Estar social previu regulação econômica pelo Estado, apoiou-se em políticas de assistência social e financiou o capital privado pelo fundo público.

Os anos de 1965 a 1973 são marcados pela rigidez do regime de acumulação, um problema que surge para a propagação capitalista. Manifesta-se então, medidas para solucionar o problema, surgindo uma sociedade e um mercado flexível, atacando os direitos trabalhistas conquistados e criam-se novas formas de consumo e produção.

Torna-se necessário então que o Estado se reconfigure, assumindo indispensáveis características, como a desregulamentação, a privatização e a descentralização, sob a alcunha de Estado Neoliberal. Colocam-se em foco as novas necessidades de produção e reprodução da existência no modelo de acumulação flexível. 
ANTUNES (1999) afirma que em seu conjunto, essas transformações têm implicado na intensificação da exploração da força de trabalho, no desemprego estrutural, no crescimento de uma desproletarização ${ }^{1}$, na precarização do trabalho, no aumento do trabalho feminino e infantil e atingido duramente a organização da classe trabalhadora.

Antunes (2007), afirma também que o resultado do neoliberalismo está por toda parte, com um alto índice de desemprego, precarização ilimitada, perda de direitos, rebaixamento salarial entre outros.

Apesar das diferenças quanto as formas de emprego flexíveis entre os diversos país, estudos realizados a nível da União Europeia apontam que, o mesmo tem vindo a aumentar em toda a Europa (CE, 1998; Brewster et al., 1997).

A difusão de formas de emprego flexíveis implica no crescimento de uma força de trabalho fluida que pode ser contratada, despedida, externalizada, de acordo com as necessidades de adaptação ao mercado por parte das empresas (CASTELLS, 1998; KOVÁCS, 2003), sendo as formas flexíveis de emprego marcadas pela precariedade (KOVÁCS, 2004, p. 35).

Em Portugal, desde início da década de 1990, tem-se procurado flexibilizar a lei trabalhista. Após a aprovação da Lei ํㅡ 64-A/89, de 27-02, que procurou flexibilizar o regime de demissões (compensando essa flexibilidade com a limitação do recurso à contratação por tempo determinado), passando pela aprovação da Lei ํㅡ 21/96, de 17-01, que consagrou a flexibilização do tempo de trabalho, e em particular a redução dos períodos normais de trabalho, pela lei que regulou o regime jurídico do trabalho a tempo parcial (Lei no 103/99, de 26-07), até ao atual Código do Trabalho. Essas medidas visam à dinamização de novas formas de contratação laboral, e à mobilidade funcional e geográfica da força-de-trabalho (REBELO, 2006).

Após a internacional crise financeira que ocorreu em 2008, o governo Português assinou o memorando com a Troika (Fundo Monetário Internacional, Comissão Europeia e Banco Central Europeu) visando o equilíbrio das contas públicas e aumento da competitividade, como condição de um empréstimo pecuniário dessas entidades que concorreu, segundo( MADUREIRA, 2014), para a criação de políticas de austeridade por parte do governo português e assistiu-se a uma perda de soberania do estado na determinação das medidas de reforma da administração pública no país.

Dentre as medidas adotadas podemos observar as reformas no mercado laboral em Portugal, com alterações na legislação trabalhista e nas medidas de proteção ao emprego. As

1 De acordo com ANTUNES (1999), desproletarização, a transferência do setor secundário para o terciário da economia. 
reformas constam diversas medidas que provocam impactos na vida do trabalhador, buscando através da flexibilização aumentar o crescimento econômico do país.

De acordo com REBELO (2004, apud SÁ, 2012), ao verificar a precariedade laboral em Portugal seguindo uma metodologia qualitativa, os trabalhadores precários possuem em seus perfis: jovens, idosos, mulheres, trabalhadores "pouco qualificados" e atuais licenciados.

Segundo SÁ (2012), Percebe-se dessa forma que há uma substituição de um conjunto de empregos - com salários superiores ao salário mínimo, há benefícios sociais, segurança no emprego - por outros com remuneração baixa, há menos benefícios e sem segurança no emprego; e por outro lado, o desemprego da população mais idosa (são indivíduos com mais de 50 anos).

Com relação ao do trabalho do professor de Educação Física, no Brasil diversos estudos vêm apontando a situação de precariedade em que se encontram os trabalhadores da área (Coimbra, 2009, Quelhas, 2013, Nozaki, 2004, Gawryszewski e Coimbra, 2008), marcados pela desvalorização da profissão no contexto escolar e pela expansão do mercado de atividades físicas no mercado não-escolar, como academias, clubes, etc...

O reordenamento do trabalho do professor de Educação Física trouxe à cena, uma série de questões referentes a essa profissão, mudanças no conteúdo do trabalho, aumento na precarização do trabalho, regulamentação da profissão e transformações no que se refere à formação profissional da área. (COIMBRA, 2009)

Assim, ALVES (2007) afirma que a precarização do trabalho é, um elemento da estrutura da "condição de proletariedade" sob o capitalismo global, caracterizada pelo aumento da taxa média de exploração, já que ocorre o aumento médio da taxa de extração de mais-valia. Em contrapartida, as vivências e experiências da precarização do trabalho são vivenciadas e captadas de jeitos distintos pelos contingentes do velho salariato e pela nova geração afundada na atual precariedade salarial. "Existe, neste caso, nos 'novos coletivos de trabalho', níveis discrepantes de experiências vividas e percebidas da 'condição de proletariedade' e do universo salarial".

O autor NOZAKI (2004) aponta ao analisar a realidade brasileira, que houve um reordenamento do trabalho do professor de Educação Física, que em sua dimensão histórica, pouco teve de conteúdo de transformação, referindo-se a uma forma de recomposição situada no interior da sobrevida do capital, como resultado de dois grandes determinantes: a 
secundarização da Educação Física na escola e a construção de uma visão de profissão liberal.

Sendo assim, o objetivo do trabalho foi verificar quais as condições trabalhistas dos Licenciados em Desporto na cidade da Guarda, analisando as transformações que ocorreram no mundo do trabalho. O estudo foi realizado com vinte e sete profissionais formados em Licenciatura em Desporto que exercem suas funções em diferentes áreas ligadas a Educação Física.

\section{Metodologia}

O referencial teórico reivindicado por essa pesquisa se assenta à luz do materialismo histórico dialético, que se consolida como uma teoria central mediada pela totalidade das relações sociais de produção, considerando seus processos históricos de contradição.

Em termos gerais, o marxismo é um enfoque teórico que contribui para desvelar a realidade, pois busca apreender o real a partir de suas contradições e relações entre singularidade, particularidade e universalidade. Esse enfoque tende a analisar o real a partir do seu desenvolvimento histórico, da sua gênese e desenvolvimento, captando as categorias mediadoras que possibilitam a sua apreensão numa totalidade (MASSON, 2012).

Buscamos compreender nosso objeto de estudo em sua totalidade, como síntese de múltiplas determinações através de subsídios teóricos em outros trabalhos desenvolvidos que se relacionam com tema pesquisado, a fim de nos embasarmos contribuindo para o avanço do conhecimento científico. Como primeiro momento, realizamos um levantamento dos estabelecimentos que oferecem trabalhos relacionados à área de Desporto na cidade da Guarda em Portugal.

Para fundamentar nossa pesquisa, utilizamos como material empírico, uma entrevista semi-estruturada contendo os seguintes temas: a) Formação profissional; b) Condições objetivas de trabalho; c) Relações trabalhistas e d) Saúde. A entrevista possui caráter anônimo, sendo assim, as falas dos interlocutores contém apenas as iniciais de seus respectivos nomes. Pretendeu-se com esses instrumentos metodológicos uma aproximação ao real movimento em que se encontra a precarização do trabalho do Licenciado em Desporto na cidade da Guarda em Portugal. 


\section{Resultados e Discussão}

O atual contexto econômico, político, e legislativo de Portugal validam e permitem um composto de moldes precários voltados ao trabalho. São distintos do modelo tradicional de contratação de trabalhadores, como exemplo os contratos a tempo parcial.

Dessa maneira, para entender o atual trabalho exercido pela classe trabalhadora, é preciso interpretar amplamente a concepção do termo trabalho. Segundo ANTUNES (2004), Ela compreende a totalidade dos assalariados, homens e mulheres que vivem da venda da sua força de trabalho, não se restringindo aos trabalhadores manuais diretos, incorporando também a totalidade do trabalho social, a totalidade do trabalho coletivo que vende sua força de trabalho como mercadoria em troca de salário.

Assim, SÁ (2010) relata que a União Europeia com o objetivo de garantir o crescimento econômico e a flexibilização tem defendido as formas "mais flexíveis de trabalho". Se essas formas de trabalho já eram marcantes em grupos de trabalhadores periféricos, elas têm se alastrado cada vez mais para outros grupos e setores.

Foram entrevistados vinte e sete profissionais de Desporto. Sendo eles, treze do sexo feminino e quatorze do sexo masculino. Com relação a faixa etária nove interlocutores possuíam até trinta anos e dezoito possuíam mais de trinta anos.

De posse das entrevistas analisamos que dezenove se formaram no Instituto Politécnico da Guarda e os oito restantes em outras instituições de ensino superior de Portugal. Dentre eles quinze são licenciados, seis cursam mestrado e seis já são mestres.

As áreas de atuação da maior parte dos profissionais são nos campos não escolares como exemplo: clubes, academias, ginásios e escolas de desportos, totalizando $66.6 \%$. Com a formação em licenciatura em desporto os profissionais são aptos a trabalharem apenas nos ambientes não escolares.

Há variações nos quesitos relacionados às condições objetivas de trabalho. Constatamos que seis profissionais exercem apenas um turno, quinze trabalham em dois turnos, cinco trabalham três turnos e um não soube responder. Verificamos que as pausas realizadas pelos interlocutores são geralmente nos horários de almoço, onde dez profissionais possuem pausa com duração de uma hora, sete profissionais com pausa de duas horas, sete profissionais não necessitam de pausa, dois profissionais possuem menos de uma hora de pausa, e um não respondeu. Os interlocutores apontaram que durante o trabalho revezam e 
saem rapidamente para lanchar, além disso, alguns interlocutores se queixaram da jornada extenuante de trabalho: Como relata S. "Como é meu dia de trabalho? Intenso. Das oito da manhã às oito e meia da noite, eu faço varias coisas no meu dia de trabalho. ". Afirma também P."As pausas são curtas, certa de dez a quinze minutos para comer qualquer coisa e entramos logo outra vez, mas são curtas.". E também M.:

Normalmente, nos dias mais preenchidos, saio de casa às oito horas, até ao meio dia e meio, "tou" a dar aulas depois tenho mais ou menos quarenta e cinco minutos para almoçar, vou dar aulas até às seis, depois lancho e regresso à casa às dez e meia, onze da noite. (M.)

No que se refere às estruturas físicas dos locais de trabalho a maior parte perfazendo um total de quinze interlocutores classificaram como boa, outros sete consideraram como muito boa um dos profissionais considera como fantástico já outro entrevistado considera a estrutura normal, um considera razoável e um classifica estrutura com falhas.

Podemos observar que os locais de trabalhos na cidade da Guarda oferecem uma boa estrutura e que há uma preocupação com a adequação do ambiente para a prática. $\mathrm{O}$ interlocutor que classificou a estrutura com falhas exerce sua função em piscinas e questiona a temperatura.

A entrevistada N. que trabalha em piscinas, afirma "A estrutura física? É boa, podíamos ter alguns ajustes, mas é boa. Em nível de companheiros de colegas também.". Afirma C.:

Sim, considero as condições fantásticas, pra pratica, para o ensino, acho que os professores de Portugal são bastantes qualificados e pronto, nós fazemos muitos estágios de maneira a termos uma maior vivência com a área, e acho que sim, acho que tudo bastante positivo cá em Portugal. (C.)

E por último N."Acho que estamos muito bem equipados, pelo o que eu conheço de cá (Guarda) penso que é um dos mais equipados e completos ginásios."

No critério relações laborais analisamos que quinze profissionais possuem contratos de trabalho, oito são prestadores de serviços e recebem por recibo verde, dois são donos do próprio negócio, um profissional possui seu próprio negócio e recebe recibo verde, e outro possui seu próprio negócio e recebe por contrato.

O contrato de trabalho trata das relações de emprego, envolvendo o empregado e o empregador. Está associado à regulamentação coletiva de trabalho, assim como aos usos laborais que não contrariem o princípio da boa fé. 
O recibo verde é uma denominação de profissionais independentes, caracteriza-se por um contrato de prestação de serviços entre o trabalhador autônomo com uma entidade contratante. Os profissionais exercem suas funções dentro da empresa, mas não são seus empregados, com relação à concepção jurídica do termo.

Recibos verdes que supostamente deveriam ser passados por trabalhadores por conta própria para fins de Imposto de Renda. Entretanto, no contexto atual do mercado de trabalho português, muitas empresas se servem deste mecanismo para não ter que contratar ou efetivar funcionários, as pessoas trabalham para as empresas como se fossem trabalhadores por conta própria e não trabalhadores dependentes. (PONTES, 2004)

São notados na pesquisa que recebem maiores salários aqueles que profissionais que possuem contratos de trabalho. Além disso, os profissionais que possuem contratos têm direitos a férias remuneradas e benefícios associados ao vencimento. Porém, há relatos de precarização no trabalho de quem recebe por contratos, o Interlocutor R. que exerce seu serviço em piscinas, afirmou que se for necessário ele trabalha aos finais de semana e não recebe por isso, as horas trabalhadas são compensadas em um outro momento. Além disso, afirmou já ter sofrido pressão no seu local de trabalho.

Ele relata que exerce seu trabalho no período noturno mesmo não recebendo adicionais noturnos e há um incentivo a sua formação continuada, desde que, tenha alguém para substituí-lo, o interlocutor recebe por esse dia, porém, há descontos no subsídio de refeição.

As condições de trabalho para quem não possui contrato são mais precárias os indivíduos que recebem por recibos verdes são considerados trabalhadores autônomos e não possui direitos básicos assegurados. Como aponta o profissional E.:

Não adoeço, não posso adoecer. Faço de tudo para não adoecer na verdade. $\mathrm{Se}$ eu, por exemplo, faltar, as aulas que eu dou durante a semana, imaginemos que numa das situações eu tenha uma lesão grave. Claro que ai sim, teria que ter alguém para me substituir, apresentar uma baixa médica. Mas isso significaria, por exemplo, que eu iria perder muitos alunos. Daí por exemplo eu não adoeço, não posso adoecer, não posso permitir que isso aconteça. (N.)

O profissional E, tem seu vencimento é calculado por números de alunos. Sendo assim, ele enfatiza que não pode adoecer sobre o risco de perder clientes e comprometer a sua remuneração. Através desses dados, observamos relações de trabalho condizentes com 
a nova configuração do trabalho no mundo contemporâneo, marcado pela flexibilização, extensas e intensas horas de trabalho.

Sobre os salários, apuramos que dez profissionais recebem mais de mil euros, esses profissionais encaixam-se em tais características: recebem por contratos, exercem suas funções em mais de um local de trabalho, e, ou são os donos dos locais de trabalhos. Como o exemplo de E. que afirmou recebe por volta de 1.700 euros, porém não recebe nenhum benefício associado ao seu vencimento e trabalha por três turnos.

Sete profissionais recebem entre quinhentos e cinquenta e sete euros à mil euros como afirma R. " Recebo por volta de mil e trezentos euros, porém ha descontos e o valor cai para novecentos euros" é um trabalhador que recebe por contrato. O total de nove profissionais recebe menos que quinhentos e cinquenta e sete euros, tal valor equivale ao salário mínimo de Portugal. Como é o caso de J. que recebe cento e cinquenta euros, trabalha setenta e duas horas no mês, recebe por recibos verde e não possui nenhum benefício associado ao seu vencimento.

Através dos relatos notamos a situação do trabalhador nessa atual etapa de acumulação de capital e concordamos com as afirmações dos autores Vasapollo (2005) apud Antunes e Pochmann (2007, p.202):

\begin{abstract}
A nova condição de trabalho está sempre perdendo mais direitos e garantias sociais. Tudo se converte em precariedade, sem qualquer garantia de continuidade: $O$ trabalhador precarizado se encontra, ademais, em uma fronteira incerta entre ocupação e não-ocupação e também em um não menos incerto reconhecimento jurídico diante das garantias sociais. Flexibilização, desregulação da relação de trabalho, ausência de direitos. Aqui a flexibilização não é riqueza. A flexibilização, por parte do contratante mais frágil, a força de trabalho é um fator de risco e a ausência de garantias aumenta essa debilidade. (VASAPOLLO, 2005 apud, ANTUNES e POCHMANN, 2007, p.202)
\end{abstract}

No critério saúde, $45 \%$ dos interlocutores relataram que possuem dificuldades em conseguir licença médica, entre eles estão os oito trabalhadores que recebem por recibos verdes, eles não possuem direito à licença sofrendo descontos em caso de falta ao trabalho. Se for necessário faltar, outro profissional exerce sua função.

Três profissionais entrevistados relataram possuir problemas de saúde decorrente da atividade exercida no trabalho. Como relata uma interlocutora S:

Possuo uma lesão, síndrome do piramidal é uma contratura do nosso músculo piramidal que é na base do glúteo, e que pronto, vou ter que ser intervencionada para libertar o músculo, porque ele contraiu e não consegue libertar, pronto. Ele esta todo contraído e faz pressão pelo ciático e faz dor, 
continua, isso é provocado às vezes pelas más posturas que assumimos e por muitos agachamentos que temos que realizar. (S.)

Além disso, todos os interlocutores relataram doenças profissionais que podem vir a desenvolver executando a profissão de desporto, as doenças podem surgir por vários fatores, entre eles más condições de trabalho. Os profissionais citaram: lesões musculares e ósseas, problemas nas cordas vocais, problemas auditivos, problemas mentais, cansaço, fadiga, doenças respiratórias, constipações. Observamos nos discursos dos interlocutores: J.:

O desgaste, ao longo dos anos vai haver uma degradação biológica em todos nós, nós ao fato de darmos tantas aulas, pode estar mais incidente a essa parte ao desgates das articulações, ou seja, é isso.(J.)

Também afirma P. :

Depende, eu este ano, por exemplo, tive uma pneumonia, que surgiu derivada as más condições climatéricas. Nós mudamos muito, andamos em ambientes frios, transpiramos em um ambiente frio depois vamos para o ambiente quente, e etc. É um dos grandes problemas que nós podemos ter, para além de outros tipos de problemas como artrose, problemas de coluna, etc, por causa do peso da manipulação dos alunos, etc. Há várias situações e nós joelhos,ombros que vai a falha como costumo dizer, mais cedo ou mais tarde. Risos. (P.)

Aponta V: "Doenças? Ah, acho que é mais doenças mentais, estou ficando maluca, às vezes, devido as pressões".

Notamos que há profissionais que sabem dos riscos que podem surgir com o desempenho do trabalho, e está consciente de que problemas podem vir a surgir. Como afirma J.:

E sim, se calhar não pensamos muito nisso, mas na parte auditiva até podemos ter algum problema por causa da música alta nos temos sempre que incentivar e é muito difícil, mas daqui alguns anos vamos pagar por isso, e depois claro, a parte muscular e óssea, porque está diretamente ligadas, agora penso que a parte auditiva é aquilo que não pensamos, e que se calhar podemos vir a sofrer.(J.)

A precarização do trabalho relaciona-se diretamente com saúde do trabalhador, o número excessivo de horas, a vida acelerada e intensa pode eliminá-lo, do mundo do trabalho, muitas vezes precocemente.

Através dos dados analisados identificamos como o reordenamento no trabalho decorrente do Estado Neoliberal e da reestruturação produtiva trouxeram impactos para a vida do licenciado em Desporto em Portugal. 


\section{Considerações Finais}

O presente estudo inseriu-se em um esforço de compreender as consequências da atual configuração do mundo do trabalho para os trabalhadores de Desporto na cidade da Guarda em Portugal. Pudemos constatar que a conjuntura do capitalismo gerou mudanças estruturais com marcas da precarização e flexibilização do trabalho.

A partir da década 70 a crise capitalista, levou o sistema a buscar formas de restabelecer o padrão de acumulação. Neste sentido é que se insere a implementação de um longo processo de reestruturação do capital, marcadas no plano político pelo neoliberalismo e no plano econômico pelo regime de acumulação flexível. Essas alterações trazem importantes consequências para a classe trabalhadora, como desmantelamento das organizações da classe, perdas de direitos duramente conquistados, com contratos de trabalhos mais flexíveis, aumento das jornadas de trabalho e menores coberturas sociais.

Observamos através dos relatos que alguns licenciados exercem suas funções e não possuem os seus direitos básicos assegurados, além disso, há trabalhadores que recebem valores a baixo do salário mínimo de Portugal. No critério saúde, há profissionais que possuem dificuldades de conseguirem baixa médica e todos os interlocutores, ironicamente, relataram doenças profissionais que podem vir a desenvolver exercendo o seu trabalho.

Por fim notamos que a precarização e a flexibilização, são questões marcantes do mercado de trabalho capitalista na contemporaneidade e tem atingido também os licenciados em desporto na cidade da Guarda. Compreender as condições de trabalho em que se encontra o profissional licenciado em desporto possui um papel significativo, o seguimento pode contribuir para a organização dos trabalhadores enfrentando as condições que lhe são impostas.

\section{Agradecimentos}

Os nossos sinceros agradecimentos ao Instituto Federal do Sudeste de Minas GeraisCampus Barbacena (IF) e ao Instituto Politécnico da Guarda (IPG) pela dedicação e o comprometimento, agradecemos também as Assessorias de Relações Internacionais do IPG e do IF.

Os professores Nuno Serra e Carolina Vila-Chã do Instituto Politécnico da Guarda pelos conhecimentos, acompanhamentos e também pelos zelos, estando sempre disponíveis 
e dispostos a ajudar e torcendo para que aproveitássemos academicamente tudo que o IPG poderia nos proporcionar.

\section{Referências}

ABRAMIDES, Maria Beatriz Costa \& CABRAL, Maria do Socorro Reis. Regime de acumulação flexível e saúde do trabalhador. São Paulo Perspec [online]. vol.17 no.1 São Paulo Jan./Mar. 2003

ALVES, Giovanni. Trabalho e subjetividade: o espírito do toyotismo na era do capitalismo manipulatório. Boitempo. São Paulo. 2011.

ANTUNES, Ricardo; ALVES, Giovanni Antonio Pinto. As mutações no mundo do trabalho na era da mundialização do capital. Educação \& Sociedade, p. 335-351, 2004.

ANTUNES, Ricardo. Os sentidos do trabalho: ensaio sobre a afirmação e a negação do trabalho. Boitempo, São Paulo. 1999.

ANTUNES, Ricardo; POCHMANN, Márcio. A desconstrução do trabalho e a explosão do desemprego estrutural e da pobreza no Brasil. Disponível em: http://biblioteca.clacso.edu.ar/clacso/clacso-crop/20120708071300/08antu2.pdf; Acesso em: maio. 2018.

BREWSTER, C. Flexible working in Europe. Journal of World Busines, Summer, v.32. 1997. GAWRYSZEWSKI, Bruno. \& COIMBRA, Tatiane Carneiro. Precarização do trabalho do professor de Educação Física sob a ação da ACAD e do CONFEF. In: Seminário do Trabalho. 6, Marília. Anais, Marília: UNESP, p. 1-16. 2008.

HARVEY, David. Condição pós-moderna. São Paulo:Loyola, 13를.2004.

KOVACKS, Ilona. Emprego Flexível em Portugal. Sociologias, Porto Alegre, ano 6, № 12, jul/dez 2004. p. 32-67.

MADUREIRA, César. A reforma da Administração Pública Central no Portugal democrático: do período pós-revolucionário à intervenção da troika. Revista de Administração Pública - RAP,49(Mayo-Junio).2015.

MASSON, Gisele. As contribuições do método materialista histórico e dialético para a pesquisa sobre políticas educacionais. Seminário de Pesquisa na região Sul, 2012. Disponível

em: <http://www.ucs.br/etc/conferencias/index.php/anpedsul/9anpedsul/paper/viewFile/966/126.> Acesso em: 01 jun. 2018.

MESZÁROS, István. (2007). O desafio e o fardo do tempo histórico: o socialismo no século XXI. Boitempo, São Paulo. 
NOZAKI, Hajime Takeuchi. Educação Física e reordenamento no mundo do trabalho: mediações da regulamentação da profissão. 2004, 383f. Tese (Doutorado em Educação)Universidade Federal Fluminense, Niterói. 2004.

OLIVEIRA, Francisco. Os direitos do antivalor: a economia política da hegemonia imperfeita. Vozes 1998. Petrópolis.

PONTES, Luciana. Mulheres brasileiras na mídia portuguesa. cadernos pagu (23), julhodezembro de 2004, pp.229-256. Disponível em: <http://www.scielo.br/pdf/cpa/n23/n23a08.> Acesso em: 30 jun. 2017.

QUELHAS, Álvaro. O profissional de Educação Física no segmento fitness: uma análise a partir da categoria marxista de trabalho produtivo. In: Seminário do Trabalho. 7., 2010, Marília. Anais... Marília: UNESP, p. 1-20. Disponível em: <https://repositorio.unesp.br/bitstream/handle/11449/101020/quelhas_aa_dr_mar.pdf?seque nce=1\&isAllowed=y $>$ Acesso em 22 de maio. 2018.

REBELO, Glória. "A reforma da Administração Pública Portuguesa ", O Economista, Anuário da Economia Portuguesa, 19ª edição: 2006, p.99 - 106.

REBELO, Glória. Flexiblidade e Precariedade no Trabalho. Fundação para a Ciência e Tecnologia. 2004.

REBELO. Glória. Flexibilidade e Diversidade Laboral em Portugal, 27 pp. 2007 ISCTE, Lisboa: Working Paper Dinâmia/ISCTE.

SÁ, Teresa. "Precariedade" e "trabalho precário": consequências sociais da precarização laboral. 2010. Disponívelem:<https://journals.openedition.org/configuracoes/203.>Acesso em: 20 jun. 2018. 